\title{
A novel diagnostic model based on differences in clinical characteristics of influenza $\mathrm{A}$ and $\mathrm{B}$
}

\author{
Xiang WeiPeng ${ }^{1}$, Che $^{1}{ }^{1}$, Zhang Miao ${ }^{1}$, Gao WuTong ${ }^{2}$, Tian Tian ${ }^{1}$, Chen GangJun ${ }^{1}$, \\ Huang YuanShun ${ }^{1}$, Zhang MinMin ${ }^{1}$, Zhang YanRong ${ }^{1}$, Liu ShengMing ${ }^{1}$, Cai XingDong ${ }^{3}$, \\ and Lai WenJia ${ }^{1}$ \\ ${ }^{1}$ Jinan University First Affiliated Hospital \\ ${ }^{2}$ Xinyi people's Hospital \\ ${ }^{3}$ Jinan University First Clinical Hospital
}

October 1, 2021

\begin{abstract}
The aim of this study is to construct a clinical distinction model to help determine the type of influenza by analyzing the clinical characteristics and hematological indicators of influenza patients during the influenza season. Demographic characteristics and clinical data of 726 influenza patients aged 7 years and older from September 2018 to July 2019 were collected, and logistic regression analysis was used to analyze the impact of different clinical manifestations and hematological examination indicators on the determination of the value of the flu type. The common clinical manifestations of influenza patients were fever (99.2\%), pharyngeal congestion $(97.1 \%)$, cough $(80.4 \%)$, sore throat $(57.2 \%)$, muscle aches $(48.8 \%)$, and runny nose (45.2\%). Those with onset of illness were 19-49 years of age $(\mathrm{OR}=0.335,95 \%$ CI: $0.196-0.573)$, nasal congestion $(\mathrm{OR}=0.566,95 \%$ CI: $0.349-0.919)$, and fever for more than 3 days $(\mathrm{OR}=0.368,95 \% \mathrm{CI}$ : 0.214-0.632) tend to diagnosed as influenza B, while those with symptoms of cough $(\mathrm{OR}=2.119,95 \%$ CI: $1.322-3.389)$, headache $(\mathrm{OR}=1.834,95 \%$ CI: $1.157-2.908)$, muscle pain $(\mathrm{OR}=1.811,95 \% \mathrm{CI}$ : 1.139-2.880), and blood CPR $>8 \mathrm{mg} / \mathrm{L}(\mathrm{OR}=2.315,95 \% \mathrm{CI}: 1.501-3.589)$ and the percentage of neutrophils $>70 \%(\mathrm{OR}=2.361$, 95\% CI: 1.171-4.759) are prone to have influenza A. Combining clinical manifestations and laboratory findings, we plotted a nomogram by lasso regression. The distinction model was discriminated using a C-index $(0.765,95 \%$ CI $0.716-0.819)$ and an AUC value (0.772,95\% CI 0.696-0.848), showing good prognostic accuracy and clinical applicability. This distinction model can distinguish well between the types of influenza, which can provide assistance in early treatment and prognosis of influenza.
\end{abstract}

\section{A novel diagnostic model based on differences in clinical characteristics of influenza A and B}

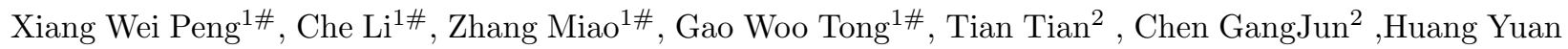
Shun ${ }^{3}$, Zhang Min Min ${ }^{4}$, Zhang Yan Rong ${ }^{5}$, Liu Sheng Ming ${ }^{6}$, Cai Xing Dong* ,Lai WenJia *

Department of Respiratory, The First Affifiliated Hospital of Jinan University, Guangzhou 510630, China and so on

*Corresponding author. E-mails: cxd19790920@sina.com/ lai-lai126.com@126.com

\# These authors contributed equally to this work.

\section{Abstract}

The aim of this study is to construct a clinical distinction model to help determine the type of influenza by analyzing the clinical characteristics and hematological indicators of influenza patients during the influenza season. Demographic characteristics and clinical data of 726 influenza patients aged 7 years and older from September 2018 to July 2019 were collected, and logistic regression analysis was used to analyze the impact of 
different clinical manifestations and hematological examination indicators on the determination of the value of the flu type. The common clinical manifestations of influenza patients were fever $(99.2 \%)$, pharyngeal congestion $(97.1 \%)$, cough $(80.4 \%)$, sore throat $(57.2 \%)$, muscle aches $(48.8 \%)$, and runny nose $(45.2 \%)$. Those with onset of illness were 19-49 years of age $(\mathrm{OR}=0.335,95 \%$ CI: $0.196-0.573)$, nasal congestion $(\mathrm{OR}=0.566,95 \% \mathrm{CI}: 0.349-0.919)$, and fever for more than 3 days $(\mathrm{OR}=0.368,95 \%$ CI: $0.214-0.632)$ tend to diagnosed as influenza $\mathrm{B}$, while those with symptoms of cough (OR=2.119, 95\% CI: 1.322-3.389), headache $(\mathrm{OR}=1.834,95 \%$ CI: 1.157-2.908), muscle pain ( $\mathrm{OR}=1.811,95 \%$ CI: $1.139-2.880)$, and blood $\mathrm{CPR}>8 \mathrm{mg} / \mathrm{L}$ $(\mathrm{OR}=2.315,95 \% \mathrm{CI}: 1.501-3.589)$ and the percentage of neutrophils $>70 \%(\mathrm{OR}=2.361,95 \% \mathrm{CI}: 1.171-4.759)$ are prone to have influenza A. Combining clinical manifestations and laboratory findings, we plotted a nomogram by lasso regression. The distinction model was discriminated using a C-index $(0.765,95 \%$ CI 0.716-0.819) and an AUC value (0.772,95\% CI 0.696-0.848), showing good prognostic accuracy and clinical applicability. This distinction model can distinguish well between the types of influenza, which can provide assistance in early treatment and prognosis of influenza.

\section{STRUCTURED ABSTRACT}

\section{Aim}

Currently, most people believe that there is no difference between influenza A and B in clinical presentation, but this is still controversial. At the same time, some articles point out that the prognosis of influenza A and B differs greatly, and we have found a difference between them in clinical treatment. Therefore, to further clarify, we conducted this study.

\section{Methods}

We used logistic regression and Lasso regression based on SPSS and R language to analyze the difference between influenza A and influenza B, and plotted a nomogram to build a clinical diagnosis prediction model.

\section{Results}

Our study found that there are indeed differences in the clinical manifestations of influenza A and B.

\section{Conclusions}

The clinical diagnostic prediction model we developed using these differences in clinical presentation can distinguish well between influenza A and B. This can help us to treat influenza A and B in a clinical setting.

\section{What's already known about this topic?}

Whether different types or subtypes of influenza have different clinical presentations remains controversial. However, there are significant differences in their prognosis.

\section{What does this article add?}

We further analyzed the differences in clinical characteristics between influenza A and B, and constructed a diagnostic prediction model based on these differences, giving us a simple method of differentiation.

Keywords Influenza A and B. Difference. Clinical manifestations. Laboratory findings. nomogram. validation.

\section{Introduction}

Influenza virus is a single-stranded RNA virus that belongs to the family orthomyxoviridae. There are currently four types of $\mathrm{ABCD}$, of which two types, $\mathrm{A}$ and $\mathrm{B}$, can cause infection in humans. Influenza is classified into different subtypes according to the different combinations of two antigens on its surface, namely haemagglutinin (HA) and neuraminidase (NA) [1], and the frequent occurrence of antigen shift leading to immune escape makes the population generally susceptible to epidemics and even pandemics [2]. Recently, the main types of influenza in the world are H1N1, H3N2 of type A, victoria, Yamagata of type B [3]. 
Seasonal influenza affects about $5-10 \%$ of adults and $20-30 \%$ of children worldwide each year, and there are 3-5 million severe cases, resulting in about 290,000-650,000 influenza-related deaths [4].

Different types or subtypes of influenza have different clinical manifestations and severity, and the results of a meta-study showed that the incidence and incubation period of influenza A ranged from 2.3-12.3\% and 1.4 days, whereas the incidence of influenza $\mathrm{B}$ ranged from $0.6 \%-5.5 \%$, with a mean incubation period of 0.6 days. In influenza A, the subtype $\mathrm{H} 3 \mathrm{~N} 2$ has a higher attack rate than $\mathrm{H} 1 \mathrm{~N} 1$ and $\mathrm{H} 2 \mathrm{~N} 2$, while N5N1 and N7N9 have a higher mortality rate than the other types [5]. Among patients hospitalized due to influenza, Martínez A and his colleagues [6] found that 1726 patients had an ICU occupancy rate of $34.5 \%$ and a mortality rate of $13.0 \%$. Influenza B increased the risk of death in the age group over 65 years, whereas in the immunosuppressed population, the H1N2 subgroup of influenza B and influenza A significantly increased the risk of death. A study of influenza in German outpatients aged 1-5 years found that $\mathrm{H} 3 \mathrm{~N} 2$ and $\mathrm{H} 1 \mathrm{~N} 1 \mathrm{pdm} 09$, as a subtype of influenza A, accounted for $56.2 \%$ and $25.8 \%$, respectively, and influenza B accounted for $18.0 \%$ of the 217 cases of influenza in children. Children with influenza B were more likely to develop pharyngitis, acute otitis media and stenosing laryngotracheitis [7]. A survey of Chinese influenza inpatients from five hospitals [8] showed that seasonal influenza caused five times more hospital mortality in 2017-2018 than in 2011-2017, with H1N1 pdm09 and influenza B predominating. The main symptoms of influenza are sudden onset of illness, fever, fatigue, headache and cough, without specific signs [9]. There is no significant difference in the distribution of symptoms and signs among patients with different types and subtypes of influenza [10]. However, due to the frequent antigenic drift of the influenza virus itself, there is a general susceptibility of the population to influenza, and the clinical manifestations still vary, as do the demographic characteristics and severity of the disease [5,8]. Delay in diagnosis and postponement of anti-influenza medication increases the risk of death in patients with influenza [11]. Thus, bohe early diagnosis, differentiation of the patient's type of influenza and prompt treatment are supposed to improve patient outcomes.

So far, there have been few reports on the differences in the clinical manifestations and severity of different types or subtypes of influenza in adults, and even fewer studies on the differences in clinical manifestations and prognosis of outpatient or inpatient influenza patients $[10,12]$. Therefore, this study analyzes the clinical characteristics and epidemiological differences between different types of outpatient and emergency influenza patients by combining the clinical symptoms, physical signs, and guided clinical practice by constructing a clinical distinction model.

\section{Materials and methods}

\section{Influenza patients and laboratory tests.}

We collected 726 patients diagnosed with influenza A or B (age[?]7 years) by influenza antibody through testpharyngeal swab from September 2018 to August 2019, of whom 306 (42.1\%) were male and 420 (57.8\%) were female. There were 447 cases of influenza A (60.7\%), aged 7-70 years (28.33+-13.64); 279 cases of influenza B (37.9\%), aged 7-75 years (24.44+-10.44); 10 cases of influenza A and B co-infection(1.4\%), aged 7-28 years (14+-7.94). Since there were too few patients with A and B influenza co-morbidity, they were not taken into comparison. Collection of upper respiratory cartilage symptoms and whether the pharynx was congested, whether the tonsils were enlarged and graded, systemic symptoms, routine blood tests and CRP in patients with influenza (Table 1). This retrospective study was approved by the ethics committee of the First Affiliated Hospital of Jinan University. Because it was a retrospective study and the patients were anonymous, the informed consent of the patients was not obtained.

\section{Patient swab sampling and influenza testing}

A nasopharyngeal swab (KANG JIAN MEDICAL, Co., Ltd.) was swabbed on the patient's tonsillar fossa and posterior pharyngeal wall, rotated for one round and immediately placed in a sampling tube, which was sent for testing within 2 hours. Upon receipt of the specimen, the laboratory used the ESPLINE Influenza Virus A+B Rapid Test Kit (Colloidal Gold Immunoassay) to detect influenza A+B virus antigens in the specimen to determine the result. 


\section{Logistic regression analysis of risk factors for different type of influenza.}

Logistic regression analysis was performed to identify independent factors for the identification of influenza in which influenza $A$ and $B$ patients were respectively a dependent variable ( $\mathrm{Y}: \mathrm{Y} 1=$ influenza $\mathrm{A}, \mathrm{Y} 0=$ influenza B) and other factors were taken as independent variables (X1, X2, X3 ...). Only significant variables (by $\chi^{2}$ test, $\left.\mathrm{p}<0.05\right)$ were incorporated into the regression equation to identify independent factors for the identification of influenza.

\section{Lasso regression and Build clinical predictive models}

Lasso regression is a method for compressed estimation of model variables. It obtains a refined model by constructing a shrinkable penalty coefficient to filter out the optimal predictor variables. With the optimal subset screened by Lasso regression, the significance of each variable in the training set was evaluated by multivariable logistic regression analysis, and a clinical distinction model was developed, and column line plots were drawn using the RMS package in R, version 4.10 (http://www.r-project.org/), using the area under the subject operating characteristic curve (AUC) and Harrell consistency index (C-index) to evaluate the predictive power of the distinction model and to calculate the accuracy and recall of the model. The consistency of the model plots with the actual observations was analyzed using calibration curves.

\section{Statistical analyses}

Statistical analysis was performed using SPSSv25.0 (SPSS Inc., Chicago, IL, USA) and R, version 4.10 (http://www.r-project.org/). Firstly, potential clinical symptoms and laboratory test data of patients with different types of influenza were firstly screened for meaningful variables by $\chi^{2}$ test(clinical characteristics including age, the season of illness, nasal congestion, cough, coughing up sputum, coughing up yellow phlegm, headache, muscle soreness and pain, duration of fever before the visit, tonsillar enlargement and score; laboratory tests including the amount of white blood cell and neutrophils, percentage of lymphocytes, percentage of monocytes, level of CRP). The above significant variables were included in the multivariate logistic regression analysis, the odds ratio of each variable for determining the type of influenza and the $95 \%$ confidence interval were calculated. Finally, the variables were screened by lasso regression to build a clinical distinction model. $\mathrm{P}<0.05$ means statistically significant.

\section{Results}

\section{Selection of target groups}

In order to assess the prevalence of influenza in the study population, we collected data and information on hospital outpatient visits, and the flowchart of case and control selections is summarized in Figure 1. There were 9601 suspected cases of influenza from September 2018 to August 2019, of which 1450 patients screened positive for influenza by swabbing the throat, with a positivity rate of $15.1 \%$, and 724 cases with incomplete data were excluded ( $49.9 \%)$, with 726 entries (50.1\%).

\section{Clinical features of influenza patients}




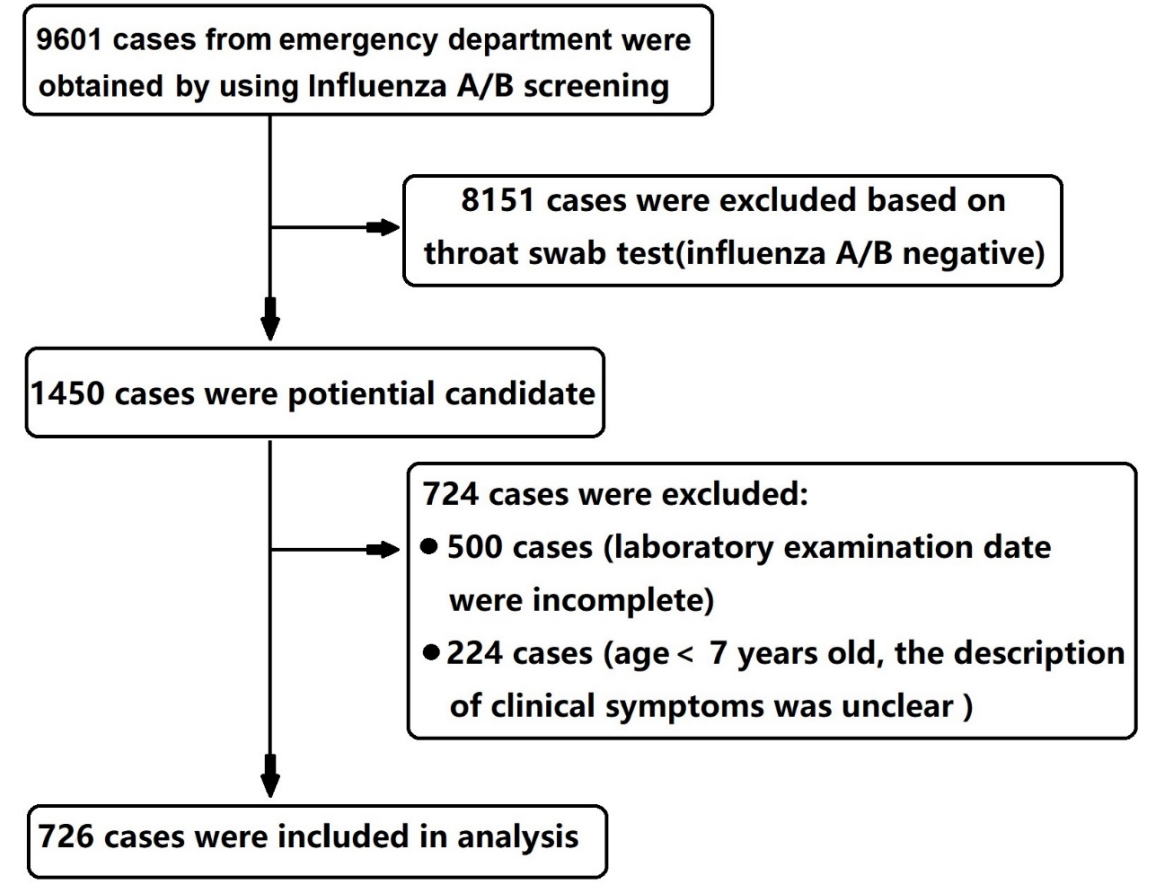

Among the 726 patients included in the study, the age of onset was 177 patients (24.4\%) aged 7-19 years, 508 patients $(70.0 \%)$ aged $19-49$ years, and 41 patients (5.6\%) aged [?]50 years. The incidence of influenza A was on the rise from September 2018 to February 2019, with the peak of the incidence in January 2019. In contrast, the incidence of influenza B was on the rise from March 2019, with a peak in May 2019 (Fig. 2A, B). There were 720 patients with fever $(99.2 \%)$, including 241 patients with a temperature $>39.1^{\circ} \mathrm{C}(33.2 \%)$. There were 584 patients with cough $(80.4 \%)$ and 415 patients with sore throat $(57.2 \%)$. The remaining common clinical symptoms were muscle pain $(48.8 \%)$, runny nose $(45.2 \%)$, headache $(40.5 \%)$, coughing sputum (38.2\%), and so on. The most common sign was pharyngeal congestion in 705 cases (97.1\%), followed by tonsillar enlargement in 230 cases $(31.8 \%)$, as shown in Table 1 and Figure 2C. Blood tests showed that among 726 influenza patients, WBC $>10 \times 109 / \mathrm{L}$ in 42 cases $(5.8 \%)$, and the total number of WBC was normal in $84.0 \%$ of influenza patients. The percentage of neutrophils $>70 \%$ was 481 cases $(66.2 \%)$, the percentage of lymphocytes $<20 \%$ was 531 cases(73.1\%), and CRP $>8 \mathrm{mg} / \mathrm{L}$ was 283 cases (39.0\%) (Table1).

Figure 1 Flowchart of patients selection. 

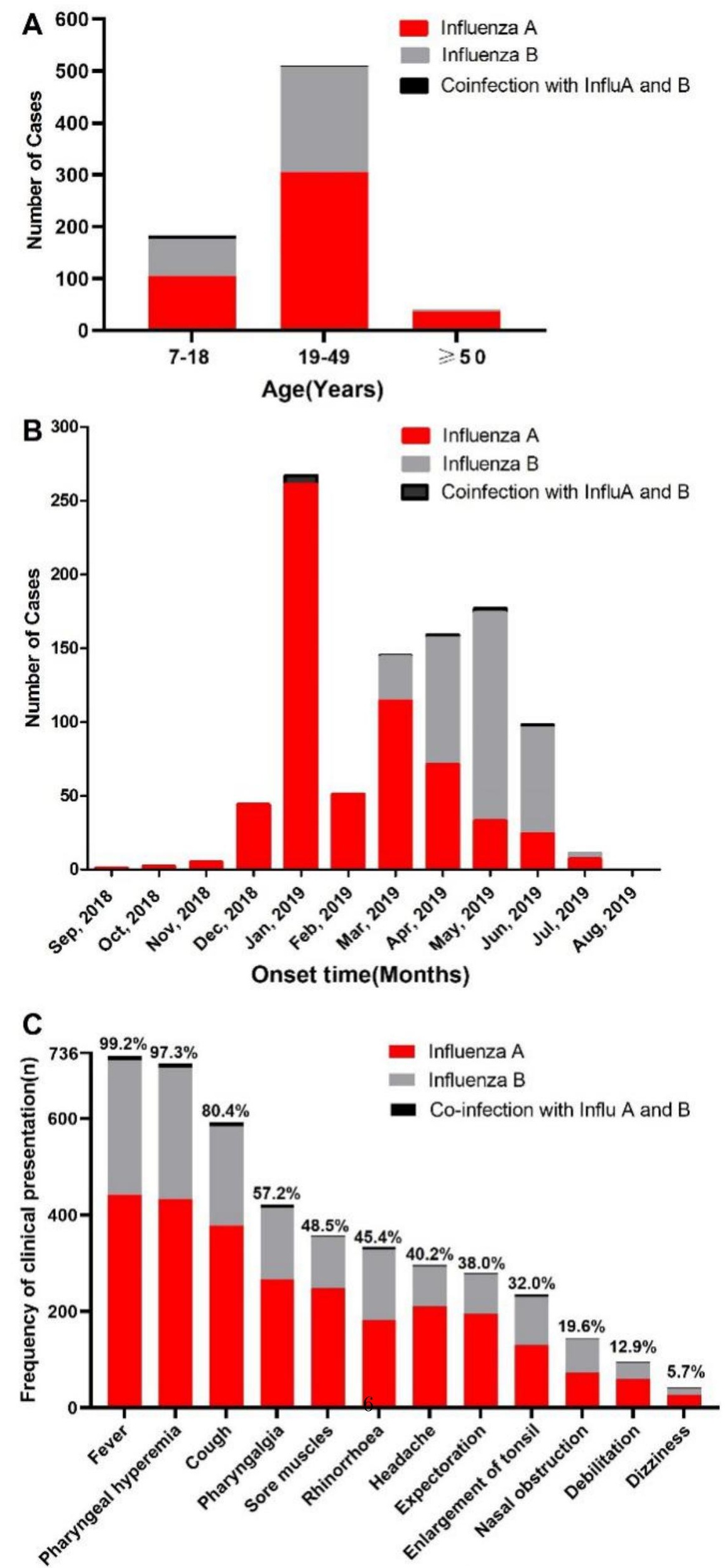
Figure 2 Demographics and clinical presentations of patients with influenzas

A, Number of influenzas onset by age group. B,Distribution of illness onset for patients with influenzas. C, Clinical presetations of patients with influenzas.

Table 1 The clinical characteristics and laboratory data of 726 patients with Influenza.

\begin{tabular}{|c|c|c|c|}
\hline Characteristics & $\mathrm{n}(\%)$ & Characteristics & $\mathrm{n}(\%)$ \\
\hline Age(year) & & Headache & \\
\hline $7-18$ & $177(24.4)$ & yes & $294(40.5)$ \\
\hline $19-49$ & $508(70.0)$ & no & $432(59.5) ? ¿ ?$ \\
\hline 50 & $41(5.6)$ & Pharyngalgia & \\
\hline Gender & & yes & $415(57.2)$ \\
\hline male & $306(42.1)$ & no & $311(42.8)$ \\
\hline female & $420(57.8)$ & Cough & \\
\hline Influenza & & yes & $584(80.4)$ \\
\hline Type A & $447(61.6)$ & no & $142(19.6)$ \\
\hline Type B & $279(38.4)$ & Expectoration & \\
\hline Influenza season & & yes & $277(38.2)$ \\
\hline fourth quarter(2018) & $43(5.9)$ & no & $449(61.8)$ \\
\hline first quarter(2019) & $339(46.7)$ & Yellow phlegm(in expectoration) & \\
\hline second quarter(2019) & $339(46.7)$ & yes & $133(48.0)$ \\
\hline third quarter(2019) & $5(0.7)$ & no & $144(52.0)$ \\
\hline Nasal obstruction & & $\mathrm{CRP}(\mathrm{mg} / \mathrm{L})$ & \\
\hline yes & $143(19.7)$ & {$[?] 8$} & $233(32.1)$ \\
\hline no & $583(80.3)$ & i8 & $283(39.0)$ \\
\hline Rhinorrhoea & & unknown & $210(28.9)$ \\
\hline yes & $328(45.2)$ & White blood cells & \\
\hline no & $398(54.8)$ & $\operatorname{normal}\left(4-10 \times 10^{9} / \mathrm{L}\right)$ & $610(84.0)$ \\
\hline Pharyngeal hyperemia & & ¡4 & $74(10.2)$ \\
\hline yes & $705(97.1)$ & ¿10 & $42(5.8)$ \\
\hline no & $21(2.9)$ & Neut $\%$ & \\
\hline Enlargement of tonsil & & $\operatorname{normal}(50 \%-70 \%)$ & $218(30.0)$ \\
\hline no & $496(68.3)$ & $¡ 50 \%$ & $27(3.7)$ \\
\hline I & $148(20.4)$ & ¿70\% & $481(66.2)$ \\
\hline II & $80(11.1)$ & Lymph\% & \\
\hline III & $2(0.3)$ & $\operatorname{normal}(20 \%-40 \%)$ & $180(24.8)$ \\
\hline Fever peak before anti-Flu & & $\lceil 20 \%$ & $531(73.1)$ \\
\hline no fever & $6(0.8)$ & $¿ 40 \%$ & $15(2.1)$ \\
\hline $37.3-38$ & $109(15.0)$ & Monocyte\% & \\
\hline $38.1-39.0$ & $370(51.0)$ & $\operatorname{normal}(3 \%-10 \%)$ & $412(56.7)$ \\
\hline $39.1-41$ & $241(33.2)$ & $¡ 3 \%$ & $2(0.3)$ \\
\hline Sore muscles & & ¿10\% & $312(43.0)$ \\
\hline yes & $354(48.8)$ & Platelet count & \\
\hline no & $372(51.2)$ & $\operatorname{normal}\left(100-300 \times 10^{12} / \mathrm{L}\right)$ & $695(95.7)$ \\
\hline Debilitation & & abnormal & $31(4.3)$ \\
\hline yes & $94(12.9)$ & Fever duration before anti-Flu(day) & \\
\hline no & $632(87.1)$ & {$[?] 1$ day } & $428(59.0)$ \\
\hline Dizziness & & $1-3$ days & $265(36.5)$ \\
\hline yes & $41(5.6)$ & {$[?] 4$ days } & $33(4.5)$ \\
\hline no & $685(94.4)$ & & \\
\hline
\end{tabular}




\section{Differences in the clinical presentation of patients with different types of influenza.}

In the age group 7-18 years and [?]50 years, there were 142 cases of influenza A $(65.1 \%, 142 / 218), 76$ cases of influenza B $(34.9 \%, 76 / 218)$. In the 19-49 age group, there were 305 cases of influenza A $(60.0 \%, 305 / 508)$, and 203 cases of influenza B $(40.0 \%, 203 / 508)$. The difference in the prevalence of influenza in different age groups was statistically significant $(\mathrm{P}<0.05)$.

In the male group, there were 188 cases of influenza A $(61.4 \%, 188 / 306), 118$ cases of influenza B $(38.6 \%$, 118/306). In the female group, there were 259 cases of influenza A $(61.7 \%, 259 / 420)$, and 161 cases of influenza B $(38.3 \%, 161 / 420)$. There was no statistically significant difference in the prevalence of influenza in the different sex groups $(\mathrm{P}>0.05)$.

In the fourth quarter, the number of patients with influenza A was 100\% (43/43), 0 patients with influenza $\mathrm{B}$ was $0 \%(0 / 43)$. In the first quarter group, there were 312 patients with influenza A $(92.0 \%, 312 / 339)$ and 27 patients with influenza B $(8.0 \%, 27 / 339)$. In the second quarter, there were 89 cases of influenza A $(26.3 \%, 89 / 339)$ and 250 cases of influenza B $(73.7 \%, 250 / 339)$. In the third quarter, there were 3 cases of influenza A $(60.0 \%, 3 / 5)$ and 2 cases of influenza B $(40.0 \%, 2 / 5)$. The difference in the prevalence of influenza in different quarter groups was statistically significant $(\mathrm{P}<0.05)$.

The remainder differences is shown in Table 2.

Table 2 The difference of clinical characteristics among patients with influenza A and B

\begin{tabular}{|c|c|c|c|c|}
\hline Item & $\operatorname{Total}(\mathrm{n})$ & Influenza A (n,\%) & Influenza B (n,\%) & $P$ value \\
\hline Age(year) Mean & & $28.33 \pm 13.64$ & $24.44 \pm 10.44$ & 0.000 \\
\hline $7-18$ & 177 & $105(59.3)$ & $72(40.7)$ & \\
\hline $19-49$ & 508 & $305(60.0)$ & $203(40.0)$ & \\
\hline$[?] 50$ & 41 & $37(90.2)$ & $4(9.8)$ & 0.001 \\
\hline \multicolumn{5}{|l|}{ Gender } \\
\hline female & 420 & $259(61.7)$ & $161(38.3)$ & 0.950 \\
\hline \multicolumn{5}{|l|}{ Influenza season } \\
\hline fourth quarter(2018) & 43 & $43(100.0)$ & $0(0)$ & \\
\hline $\begin{array}{l}\text { first } \\
\text { quarter(2019) }\end{array}$ & 339 & $312(92.0)$ & $27(8.0)$ & \\
\hline $\begin{array}{l}\text { second } \\
\text { quarter(2019) }\end{array}$ & 339 & $89(26.3)$ & $250(73.7)$ & \\
\hline $\begin{array}{l}\text { third } \\
\text { quarter(2019) }\end{array}$ & 5 & $3(60.0)$ & $2(40.0)$ & 0.000 \\
\hline \multicolumn{5}{|l|}{ Nasal obstruction } \\
\hline yes & 143 & $73(51.0)$ & $70(49.0)$ & \\
\hline no & 583 & $374(64.2)$ & $209(35.8)$ & 0.004 \\
\hline \multicolumn{5}{|l|}{ Rhinorrhoea } \\
\hline yes & 328 & $182(55.5)$ & $146(44.5)$ & \\
\hline no & 398 & $265(66.6)$ & $133(33.4)$ & 0.002 \\
\hline \multicolumn{5}{|l|}{$\begin{array}{l}\text { Pharyngeal } \\
\text { hyperemia }\end{array}$} \\
\hline yes & 705 & $433(61.4)$ & $272(38.6)$ & \\
\hline no & 21 & $14(66.7)$ & $7(33.3)$ & 0.626 \\
\hline \multicolumn{5}{|l|}{$\begin{array}{l}\text { Enlargement of } \\
\text { tonsil }\end{array}$} \\
\hline no & 496 & $317(63.9)$ & $179(36.1)$ & \\
\hline I & 148 & $75(50.7)$ & $73(49.3)$ & \\
\hline II & 80 & $53(66.3)$ & $27(33.8)$ & \\
\hline
\end{tabular}




\begin{tabular}{|c|c|c|c|c|}
\hline Item & Total(n) & Influenza A $(\mathrm{n}, \%)$ & Influenza B $(\mathrm{n}, \%)$ & $P$ value \\
\hline III & 2 & $2(100.0)$ & $0(0)$ & 0.011 \\
\hline \multicolumn{5}{|c|}{$\begin{array}{l}\text { Fever peak before } \\
\text { anti-Flu }\end{array}$} \\
\hline no fever & 6 & $5(83.3)$ & 1(16.7) & \\
\hline $37.3-38$ & 109 & $71(65.1)$ & $38(34.9)$ & \\
\hline $38.1-39.0$ & 370 & $219(59.2)$ & $151(40.8)$ & \\
\hline $39.1-41$ & 241 & $152(63.1)$ & $89(36.9)$ & 0.382 \\
\hline \multicolumn{5}{|c|}{ Sore muscles } \\
\hline yes & 354 & $248(70.1)$ & $106(29.9)$ & \\
\hline no & 372 & $199(53.5)$ & $173(46.5)$ & 0.000 \\
\hline \multicolumn{5}{|c|}{ Debilitation } \\
\hline yes & 94 & $60(63.8)$ & $34(36.2)$ & \\
\hline no & 632 & $387(61.2)$ & $245(38.8)$ & 0.629 \\
\hline \multicolumn{5}{|l|}{ Dizziness } \\
\hline yes & 41 & $27(65.9)$ & $14(34.1)$ & \\
\hline no & 685 & $420(61.3)$ & $265(38.7)$ & 0.562 \\
\hline \multicolumn{5}{|l|}{ Headache } \\
\hline yes & 294 & $210(71.4)$ & $84(28.6)$ & \\
\hline no & 432 & $237(54.9)$ & $195(45.1)$ & 0.000 \\
\hline \multicolumn{5}{|c|}{ Pharyngalgia } \\
\hline yes & 415 & $266(64.1)$ & $149(35.9)$ & \\
\hline no & 311 & $181(58.2)$ & $130(41.8)$ & 0.106 \\
\hline \multicolumn{5}{|l|}{ Cough } \\
\hline yes & 584 & $378(64.7)$ & $206(35.3)$ & \\
\hline no & 142 & $69(48.6)$ & $73(51.4)$ & 0.000 \\
\hline \multicolumn{5}{|c|}{ Expectoration } \\
\hline yes & 277 & $195(70.4)$ & $82(29.6)$ & \\
\hline no & 449 & $252(56.1)$ & $197(43.9)$ & 0.000 \\
\hline \multicolumn{5}{|c|}{$\begin{array}{l}\text { Yellow phlegm(in } \\
\text { expectoration) }\end{array}$} \\
\hline yes & 133 & $87(65.4)$ & $46(34.6)$ & \\
\hline no & 144 & $100(69.4)$ & $44(30.6)$ & 0.474 \\
\hline \multirow{3}{*}{\multicolumn{5}{|c|}{$\begin{array}{l}\text { Fever duration } \\
\text { before } \\
\text { anti-Flu(day) }\end{array}$}} \\
\hline & & & & \\
\hline & & & & \\
\hline [?]1 day & 428 & $292(68.2)$ & $136(31.8)$ & \\
\hline $1-3$ days & 265 & $141(53.2)$ & $124(46.8)$ & \\
\hline$[?] 4$ days & 33 & $14(42.4)$ & $19(57.6)$ & 0.000 \\
\hline
\end{tabular}

Differences in haematological parameters in patients with different types of influenza.

In the group with elevated leukocytes, there were 31 patients with influenza A $(73.8 \%, 31 / 42)$, 11 patients with influenza B $(26.2 \%, 11 / 42)$. In the group with normal leukocytes, there were 389 patients with influenza A $(63.8 \%, 389 / 610), 221$ patients with influenza B $(36.2 \%, 221 / 610)$. There were 27 cases of influenza A $(36.5 \%, 27 / 74), 47$ cases of influenza B $(63.5 \%, 47 / 74)$ in the leukocyte-decreasing group. The difference in the prevalence of influenza in different levels of leukocyte groups was statistically significant $(\mathrm{P}<0.05)$.

See Table 3 for the rest.

Table 3 The difference of laboratory data among patients with influenza A and B 


\begin{tabular}{|c|c|c|c|c|}
\hline Item & $\operatorname{Total}(\mathrm{n})$ & Influenza $\mathrm{A}(\mathrm{n}, \%)$ & Influenza B (n,\%) & $P$ value \\
\hline \multicolumn{5}{|c|}{ White blood cells } \\
\hline $4-10 \times 10^{9} / \mathrm{L}$ & 610 & $389(63.8)$ & $221(36.2)$ & \\
\hline ¿10×109\% /L & 42 & $31(73.8)$ & $11(26.2)$ & \\
\hline ¡ $4 \times 10^{9} / \mathrm{L}$ & 74 & $27(36.5)$ & $47(63.5)$ & 0.000 \\
\hline \multicolumn{5}{|l|}{ Neut $\%$} \\
\hline $50 \%-70 \%$ & 218 & $95(43.6)$ & $123(56.4)$ & \\
\hline ¿70\% & 481 & $343(71.3)$ & $138(28.7)$ & \\
\hline$¡ 50 \%$ & 27 & $9(33.3)$ & $18(66.7)$ & 0.000 \\
\hline \multicolumn{5}{|l|}{ Lymph\% } \\
\hline $20 \%-40 \%$ & 180 & $75(41.7)$ & $105(58.3)$ & \\
\hline ¿40\% & 15 & $5(33.3)$ & $10(66.7)$ & \\
\hline$¡ 20 \%$ & 531 & $367(69.1)$ & $164(30.9)$ & 0.000 \\
\hline \multicolumn{5}{|l|}{ Monocyte\% } \\
\hline $3 \%-10 \%$ & 412 & $268(65.0)$ & $144(35.0)$ & \\
\hline ¿10\% & 312 & $179(57.4)$ & $133(42.6)$ & \\
\hline j3\% & 2 & $0(0.0)$ & $2(100.0)$ & 0.016 \\
\hline \multicolumn{5}{|l|}{$\mathrm{CRP}(\mathrm{mg} / \mathrm{L})$} \\
\hline [?]8 & 233 & $99(42.5)$ & $134(57.5)$ & \\
\hline ¿8 & 283 & $182(64.3)$ & $101(35.7)$ & \\
\hline unknown & 210 & $166(79.0)$ & $44(21.0)$ & 0.000 \\
\hline \multicolumn{5}{|l|}{ NLR } \\
\hline$[?] 5$ & 349 & $163(46.7)$ & $177(50.7)$ & \\
\hline i5 & 387 & $284(73.4)$ & $102(26.4)$ & \\
\hline \multicolumn{5}{|l|}{ LMR } \\
\hline$[?] 2$ & 518 & $351(67.8)$ & $167(32.2)$ & \\
\hline ¿2 & 208 & $96(46.2)$ & $112(53.8)$ & 0.000 \\
\hline
\end{tabular}

Note: NLR:Neutrophil-lymphocyte ratio; LMR: Lymphocyte-monocyte ratio; All abnormal data was compared with normal data.

\section{Logistic regression analysis of influenza patients' clinical manifestations and hematological parameters to determine the type of influenza.}

In 726 patients with influenza, logistic regression analysis included eight variables: age of onset, nasal congestion, fever for more than 3 days, cough, headache, muscle aches, blood CPR $>8 \mathrm{mg} / \mathrm{L}$, and neutrophil percentage $>70 \%$. Patients aged $19-49$ years $(\mathrm{OR}=0.335,95 \% \mathrm{CI}: 0.196-0.573)$, with nasal congestion $(\mathrm{OR}=$ 0.566, 95\% CI: $0.349-0.919)$ and fever for more than 3 days ( $\mathrm{OR}=0.368,95 \%$ CI: $0.214-0.632)$ were more likely to be diagnosed with influenza $\mathrm{B}(\mathrm{P}<0.01)$. and symptoms of cough $(\mathrm{OR}=2.119,95 \%$ CI: 1.322 3.389), headache ( $\mathrm{OR}=1.834,95 \% \mathrm{CI}: 1.157-2.908)$, muscle pain ( $\mathrm{OR}=1.811,95 \% \mathrm{CI}: 1.139-2.880)$, and blood CPR $>8 \mathrm{mg} / \mathrm{L}(\mathrm{OR}=2.315,95 \%$ CI: 1.811, 95\% CI: 1.139-2.880). CI: 1.501-3.589) and neutrophil percentage $>70 \%(\mathrm{OR}=2.361,95 \%$ CI: $1.171-4.759)$ patients were more likely to be diagnosed with influenza A (Figure 3). 


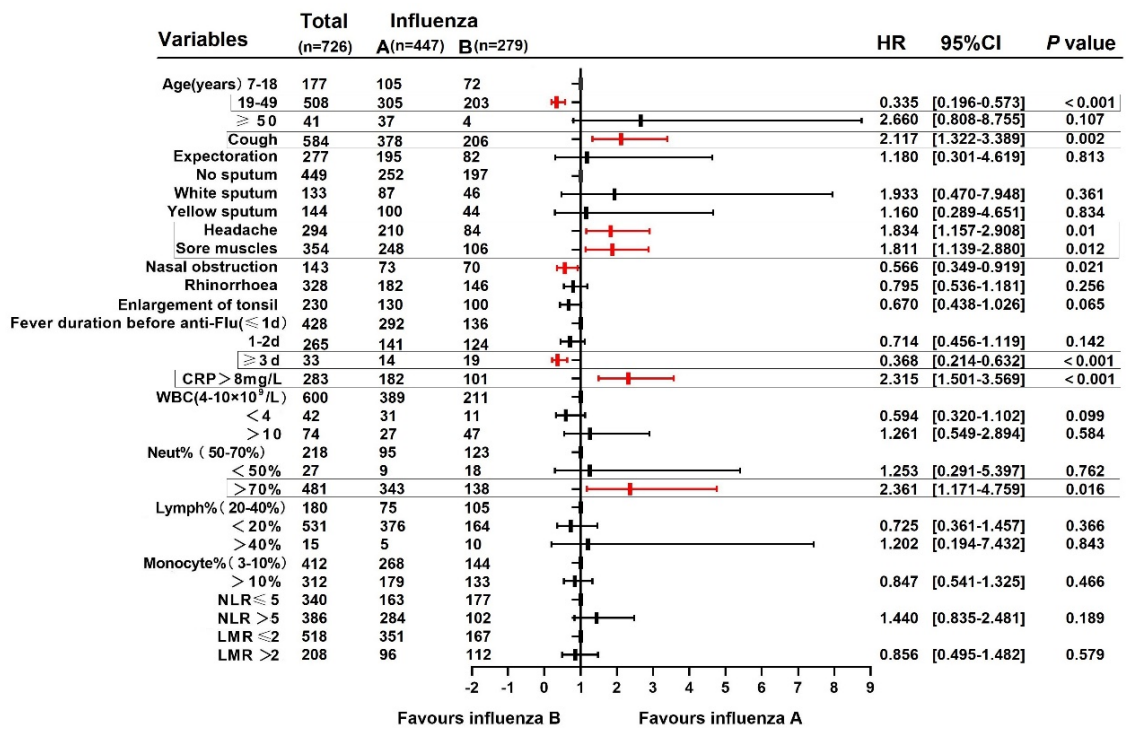

Figure 3 Logistic regression analysis of risk factors for influenza A and B

\section{Nomograms and Model Performance}

After performing multifactorial logistic regression, We found several characteristics to help us determine whether a patient might be diagnosed with influenza A. However, this method lacks quantitative indicators, so we developed a clinical distinction model to help us better distinguish between influenza A and B.

Among 726 patients diagnosed with influenza A or B (age [?]7 years), 488 patients ultimately met the inclusion criteria after removing samples with missing values. Using a random assignment method, patients were randomly divided into a primary cohort and a validation cohort split in a 7:3 ratio. Finally, the primary cohort contained 338 patients, while the validation cohort contained 150 patients. All baseline characteristics of the training cohort and validation cohort are shown in Table 4. There were no significant differences in baseline characteristics between the primary and validation cohorts $(\mathrm{p}>0.05)$, except for hemoglobin.

Table 4 Comparison of basic demographics, vital signs, laboratory tests and Number of people diagnosed with Influenza A between the primary cohort and the validation cohort

\begin{tabular}{|c|c|c|c|c|}
\hline Variables & $\begin{array}{l}\text { Training cohort } \\
\mathrm{n}=338\end{array}$ & $\begin{array}{l}\text { Training cohort } \\
\mathrm{n}=338\end{array}$ & $\begin{array}{l}\text { Validation cohort } \\
\mathrm{n}=150\end{array}$ & $P$-value \\
\hline Male, $\mathrm{n}(\%)$ & Male, $\mathrm{n}(\%)$ & $152(45.0)$ & $59(39.3)$ & 0.2460 \\
\hline Age, years & Age, years & $25.95 \pm 12.12$ & $26.67 \pm 14.44$ & 0.5477 \\
\hline $\begin{array}{l}\text { White blood cell, } \\
\times 10^{9} / \mathrm{L}\end{array}$ & $\begin{array}{l}\text { White blood cell, } \\
\times 10^{9} / \mathrm{L}\end{array}$ & $6.36 \pm 2.27$ & $6.05 \pm 2.05$ & 0.1345 \\
\hline $\begin{array}{l}\text { Neutrophil, } \\
\times 10^{9} / \mathrm{L}\end{array}$ & $\begin{array}{l}\text { Neutrophil, } \\
\times 10^{9} / \mathrm{L}\end{array}$ & $4.76 \pm 2.19$ & $4.46 \pm 1.84$ & 0.1226 \\
\hline $\begin{array}{l}\text { Lymphocyte, } \\
\times 10^{9} / \mathrm{L}\end{array}$ & $\begin{array}{l}\text { Lymphocyte, } \\
\times 10^{9} / \mathrm{L}\end{array}$ & $0.99 \pm 0.61$ & $0.94 \pm 0.45$ & 0.3540 \\
\hline NLR & NLR & $6.43 \pm 5.29$ & $6.10+4.48$ & 0.4769 \\
\hline $\begin{array}{l}\text { Mononuclear cell, } \\
\times 10^{9} / \mathrm{L}\end{array}$ & $\begin{array}{l}\text { Mononuclear cell, } \\
\times 10^{9} / \mathrm{L}\end{array}$ & $0.57 \pm 0.20$ & $0.56 \pm 0.23$ & 0.8689 \\
\hline NMR & NMR & $1.90 \pm 1.20$ & $1.84 \pm 1.04$ & 0.5757 \\
\hline HGB, g/L & HGB, g/L & $140.62 \pm 15.87$ & $137.49 \pm 14.30$ & 0.0321 \\
\hline $\mathrm{PLT}, \times 10^{9} / \mathrm{L}$ & $\mathrm{PLT}, \times 10^{9} / \mathrm{L}$ & $198.71 \pm 49.46$ & $196.26+52.44$ & 0.6279 \\
\hline
\end{tabular}




\begin{tabular}{|c|c|c|c|c|}
\hline Variables & $\begin{array}{l}\text { Training cohort } \\
\mathrm{n}=338\end{array}$ & $\begin{array}{l}\text { Training cohort } \\
\mathrm{n}=338\end{array}$ & $\begin{array}{l}\text { Validation cohort } \\
\mathrm{n}=150\end{array}$ & $P$-value \\
\hline CRP, mg/L & $\mathrm{CRP}, \mathrm{mg} / \mathrm{L}$ & $12.99 \pm 13.56$ & $13.45 \pm 14.18$ & 0.7832 \\
\hline $\begin{array}{l}\text { Pharyngalgia, } \\
\mathrm{n}(\%)\end{array}$ & $\begin{array}{l}\text { Pharyngalgia, } \\
\mathrm{n}(\%)\end{array}$ & $186(55.0)$ & $83(55.3)$ & 0.9500 \\
\hline Cough, n(\%) & Cough, n $(\%)$ & $261(77.2)$ & $122(81.3)$ & 0.3070 \\
\hline $\begin{array}{l}\text { Expectoration, } \\
\mathrm{n}(\%)\end{array}$ & $\begin{array}{l}\text { Expectoration, } \\
\mathrm{n}(\%)\end{array}$ & $108(32.0)$ & $52(34.7)$ & 0.5560 \\
\hline Headache, $\mathrm{n}(\%)$ & Headache, $\mathrm{n}(\%)$ & $150(44.4)$ & $59(39.3)$ & 0.2990 \\
\hline $\begin{array}{l}\text { Dizziness or } \\
\text { dizziness, } \mathrm{n}(\%)\end{array}$ & $\begin{array}{l}\text { Dizziness or } \\
\text { dizziness, } \mathrm{n}(\%)\end{array}$ & $16(4.7)$ & $10(6.7)$ & 0.3800 \\
\hline $\begin{array}{l}\text { Sore muscles, } \\
\mathrm{n}(\%)\end{array}$ & $\begin{array}{l}\text { Sore muscles, } \\
\mathrm{n}(\%)\end{array}$ & $178(52.7)$ & $69(46.0)$ & 0.1740 \\
\hline Debilitation, $\mathrm{n}(\%)$ & Debilitation, $\mathrm{n}(\%)$ & $48(14.2)$ & $15(10.0)$ & 0.2020 \\
\hline $\begin{array}{l}\text { Pharyngeal } \\
\text { hyperemia, n(\%) }\end{array}$ & $\begin{array}{l}\text { Pharyngeal } \\
\text { hyperemia, } \mathrm{n}(\%)\end{array}$ & $330(97.6)$ & $144(96.0)$ & 0.3190 \\
\hline $\begin{array}{l}\text { Enlargement of } \\
\text { tonsil, } n(\%)\end{array}$ & $\begin{array}{l}\text { Enlargement of } \\
\text { tonsil, } \mathrm{n}(\%)\end{array}$ & $101(29.9)$ & $46(30.7)$ & 0.8620 \\
\hline $\begin{array}{l}\text { Nasal congestion, } \\
\mathrm{n}(\%)\end{array}$ & $\begin{array}{l}\text { Nasal congestion, } \\
\mathrm{n}(\%)\end{array}$ & $71(21.0)$ & $30(20.0)$ & 0.8000 \\
\hline $\begin{array}{l}\text { Rhinorrhoea, } \\
\mathrm{n}(\%)\end{array}$ & $\begin{array}{l}\text { Rhinorrhoea, } \\
\mathrm{n}(\%)\end{array}$ & $145(42.9)$ & $70(46.7)$ & 0.4390 \\
\hline $\begin{array}{l}\text { The time from } \\
\text { fever to taking } \\
\text { oseltamivir,days }\end{array}$ & $\begin{array}{l}\text { The time from } \\
\text { fever to taking } \\
\text { oseltamivir,days }\end{array}$ & $1.62 \pm 1.00$ & $1.61 \pm 1.03$ & 0.9602 \\
\hline $\begin{array}{l}\text { Fever peak before } \\
\text { anti Flu, }\end{array}$ & $\begin{array}{l}\text { Fever peak before } \\
\text { anti Flu, }\end{array}$ & $38.83 \pm 0.67$ & $38.89 \pm 0.72$ & 0.3207 \\
\hline Flu, $\mathrm{n}(\%)$ & Flu, n $(\%)$ & $184(54.4)$ & $84(56.0)$ & 0.7490 \\
\hline
\end{tabular}

Note: The mean \pm SD or frequency (percentage) of each variable is reported according to the different data types. Continuous variables were compared using the Student's t-test. And $\mathrm{X}^{2}$ tests were used to compare differences between categorical variables.

NLR: Neutrophil-lymphocyte ratio; LMR: Lymphocyte-monocyte ratio; NMR: Neutrophil- mononuclear ratio.

Feature selection for binary logistic regression models based on the least absolute shrinkage and selection operator (LASSO). Tuning parameter $(\lambda)$ selection in the lasso model was cross-validated by using a 10 -fold crossover for the minimum criterion. The area under the subject working characteristic (AUC) curve was plotted versus $\log (\lambda)$ (Fig.4A). Vertical lines were plotted using the minimum criterion and 1 standard error of the minimum criterion (1-SE criterion) at the optimal value. The $\log (\lambda)$ was chosen to be 0.1058 (1-SE criterion) based on the results of 10 cross-validation selections and the principle of less feature inclusion. (Fig.4B) Lasso coefficient profiles of 24 texture features. Coefficient profiles were plotted based on the $\log (\lambda)$ sequence. Ten cross-validations were used to plot vertical lines on selected values where the best $\lambda$ corresponds to four non-zero coefficients, including neutrophil, CRP, headache, and sore muscles. The p-values for the variables included in the model were all less than 0.05. (Table 5). 

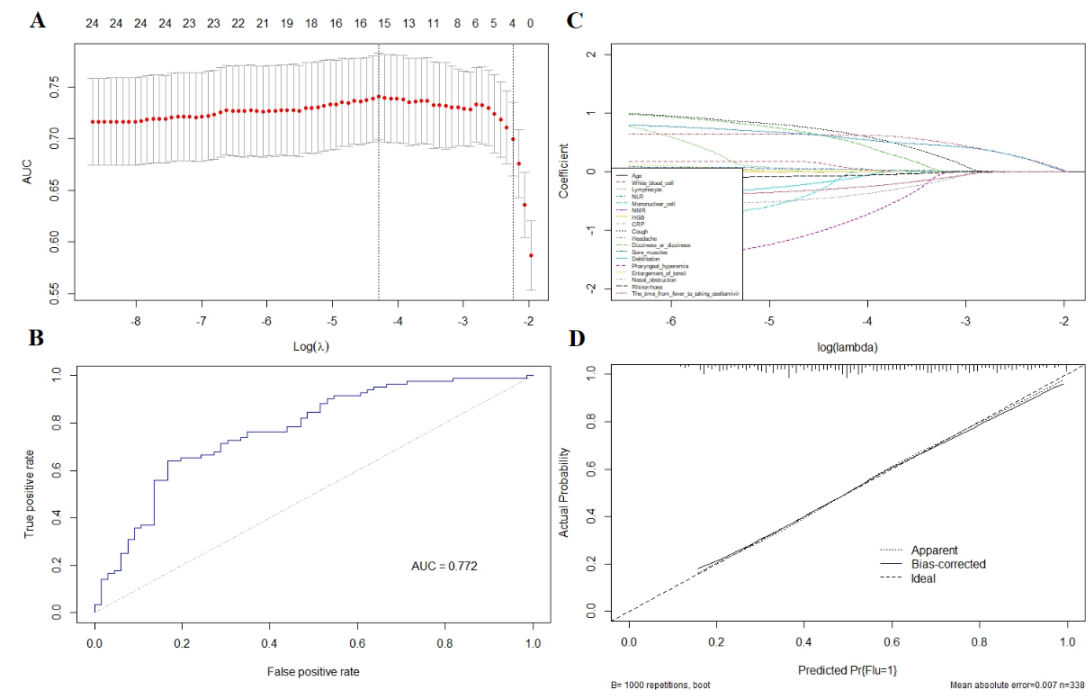

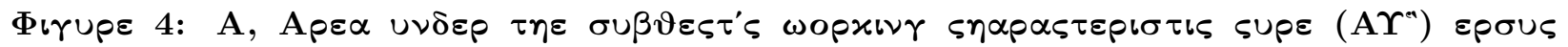

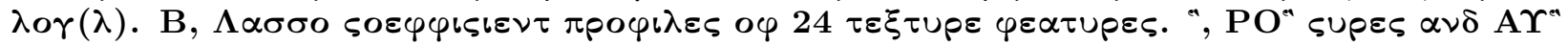

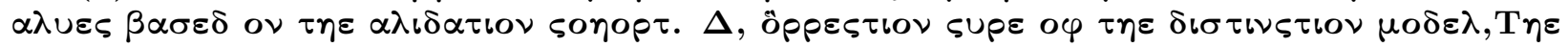

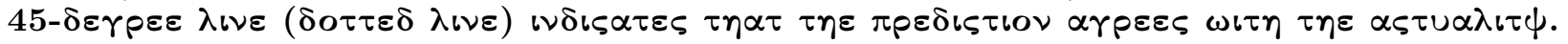

Table 5 Multivariable Logistic Regression Analyses for the relationship between the candidate risk factors and number of people diagnosed with Influenza A in the training cohort

\begin{tabular}{llll}
\hline Variable & $\beta$ & OR $(95 \%$ CI $)$ & $P$-Value \\
\hline CRP & 0.0392 & $1.6498(1.1559-2.3547)$ & $<0.0058$ \\
Headache & 0.7464 & $2.1094(1.1854-3.7538)$ & 0.0112 \\
Neutrophil & 0.3147 & $2.3575(1.6391-3.3909)$ & $<0.0001$ \\
Sore muscles & 0.7470 & $2.1106(1.1850-3.7592)$ & 0.0112 \\
\hline
\end{tabular}

Note: OR values were estimated by logistic regression. All statistical tests were two-sided. The final distinction model was selected by Lasso regression of the compressed variables.

A weighted score was assigned to each independent prognostic parameter by a multivariate logistic model and a nomogram was drawn (Figure 5). Neutrophils, CRP, Headache, and Sore muscles corresponded to different scores, and the probability score for the diagnosis of influenza A ranged from 0.05 to 0.99 . The higher score calculated from the sum of the assigned scores for each prognostic factor in the nomogram corresponded to the probability of the diagnosis of influenza A. 


\section{Nomogram}

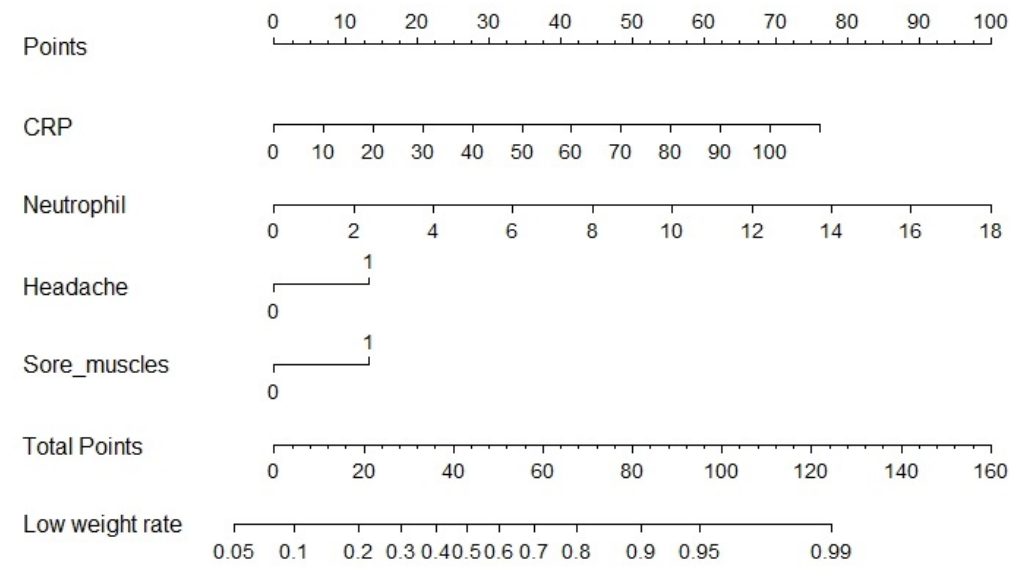

Figure 5: Nomogram were developed for predicting the probability of influenza A based on the primary cohort, with model features including Neutrophils, CRP, Headache, and Sore muscles.

We validate the distinction model with data from the validation cohort using bootstrap validation. The C-index was 0.765 (95\% CI 0.716-0.819), the accuracy was $73 \%$ and the recall sensitivity was $73 \%$, while the ROC curve was plotted(Fig.4C) and its AUC value was 0.772(95\% CI 0.696-0.848). With these indicators, it can be seen that the nomogram has good accuracy in estimating the risk of influenza $\mathrm{A}$. In addition, we also plotted the calibration and we can see that the model curve almost coincides with the 45-degree line(Fig.4D), This suggests that there is good agreement between the estimated risk of the distinction model and the pharyngeal swab results.

\section{Discussion}

The study shows that between winter 2018 and fall 2019, influenza was predominantly influenza A. Young people had a higher prevalence of influenza than the old and young, and both men and women were more likely to develop influenza A. The prevalence of influenza A was higher in young people than in old people. The onset of influenza A peaks in January 2019 and then gradually declines before influenza B reaches its peak, mainly in the winter and spring. In contrast, influenza B peaked in May 2019 and was concentrated in the spring. This is similar to the epidemiological findings of Zhu et al [13]. This study observed a $16.6 \%$ influenza detection rate in local hospitals in Yichang City from 2013-2019, mostly in winter and spring, with a complex variety of dominant subtypes and lineages, and a higher rate of influenza A positivity (10.6\%) than influenza B positivity (5.9\%). In addition, we found that women appear to be more susceptible to influenza than men, which is consistent with the findings of a previous study that noted higher humoral and cell-mediated immune responses to viral antigens in women have been shown to play an important role in determining gender variability in viral infections [14].

This study observed that almost all influenza patients have a fever and pharyngeal congestion, and other common manifestations include cough, sore throat, muscle aches, runny nose, headache, coughing up sputum, and enlarged tonsils. This provides good guidance for our clinical activities. Single-factor analysis found that influenza $\mathrm{A}$ is more likely to have fever, cough, sore throat, and muscle aches than influenza B. Regression analysis found that influenza $\mathrm{A}$ is more likely to have a cough, headache, and muscle aches, while influenza $\mathrm{B}$ is more likely to have nasal congestion and fever for more than 3 days. In other words, patients with diverse symptoms of influenza are more likely to be diagnosed with influenza A. A prospective study conducted in Taiwan on adults aged 28-50 years [15] showed that fever and cough had the highest sensitivity (86\%) and 
fever, cough, and sneezing had the highest specificity (77\%) for influenza. A retrospective cross-sectional study[16] conducted in an urban emergency department in the United States found that the best predictive model for identifying influenza at all ages included cough (OR value 5.87), fever (OR value 4.49), runny nose (OR value 1.98), and myalgia (OR value 1.44). Another prospective study [17] found that cough (OR value 6.4 ), as well as fever (OR value 3.0), were the most predictive of influenza among adults over 60 years of age in six hospital emergency rooms. However, Irving SA [18] found no difference in clinical presentation between influenza A and influenza B during the influenza season. A meta-analysis [19] pointed out that there was little difference in the clinical presentation of patients with different types of influenza virus infections. In terms of blood tests, common abnormalities include a neutrophil count $>70 \%$ and a lymphocyte count $<20 \%$. We know that one of the unique features of influenza is pulmonary complications such as pneumonia, including primary influenza viral pneumonia and secondary bacterial pneumonia [20]. However, during an influenza outbreak, many patients do not clearly adapt to any of these manifestations and may instead suffer from a mix of viral and bacterial pneumonia. Unfortunately, chest X-ray data were not available.

It should also be noted that the time and place of collection of respiratory specimens can affect the results of influenza testing, with respiratory specimens collected 48-72 hours after the onset of influenza being less sensitive for influenza screening analyses (e.g., rapid diagnostic tests) due to increased influenza virus shedding during this period[21]. A meta-analysis of observational studies of rapid influenza antigen testing of respiratory specimens compared with molecular analysis or viral culture [22] showed that rapid influenza antigen testing has moderate sensitivity (62\%) and high specificity (98\%). Admittedly, the diagnosis of influenza needs to be supported by positive laboratory results, but we cannot rely solely on influenza antigen testing to guide treatment; symptomatology and clinical experience are equally essential. This study suggests that patients in the emergency department who are at high risk for suspected influenza can be treated empirically with antiviral therapy, regardless of positive or negative influenza antigen test results. Certainly, confirmation of testing for influenza could reduce unnecessary antibiotic use (especially with low calcineurin levels, indicating a low likelihood of bacterial infection) and improve antibiotic management. Although the sudden onset of fever with cough is a common manifestation of influenza, signs and symptoms may be different in patients with different underlying conditions. This is why this study was conducted, as the symptoms of influenza are diverse, and it is important to be able to quickly determine the type of influenza and intervene in a timely manner based on simple clinical manifestations and routine blood results. Previous studies have paid more attention to the clinical manifestations and differences of influenza-associated pneumonia, but not enough attention has been paid to the characteristics of early influenza. In fact, in a highly mobile department like the emergency department, it is very meaningful to quickly and accurately determine the type of influenza so that early intervention can be made, which is of great help in determining the prognosis.

In this study, it was found that blood CPR $>8 \mathrm{mg} / \mathrm{L}$ and neutrophil percentage $>70 \%$ were 2.3 times more likely to diagnose influenza A than influenza B. Also, influenza A has a higher NLR, suggesting that influenza A has a more pronounced inflammatory response in its early stages, is more likely to be associated with bacterial infections, and maybe more severe, which is closely related to the higher hospitalization rate and poorer prognosis of influenza A $[19,23]$. Previous studies have suggested that influenza $A$ is more severe than influenza B [24-27] because influenza A-associated pneumonia is more common, with more severe respiratory symptoms, longer hospital stays, and a higher probability of requiring mechanically assisted ventilation [28]. Curbelo J[29] concluded that the mortality rate of influenza-associated pneumonia is strongly associated with high NLR. Therefore, early identification of the type of influenza and early administration of medication according to the type is an advantageous measure to reduce serious complications. For children, Livia et al [30] concluded that there was no significant difference in CRP levels between patients with influenza A and influenza B and that the frequency of elevated CRP was similar in both. The majority of those enrolled in this study were adults, and CRP can rise rapidly in combination with bacterial infections, so the results were different.

The clinical classification of influenza has a great influence on the prognosis of the condition. Therefore, more data are needed to support the identification of influenza types. Fever, cough, sore throat, and other symptoms of upper respiratory tract infection remain the most common symptoms of influenza. In conclusion, 
our study shows that patients with cough, muscle aches and pains, significantly elevated blood CRP and neutrophil percentage are more likely to have influenza A. We used these differences in clinical manifestations and laboratory findings to draw a nomogram. This helps us to quickly predict the type of influenza by simple indicators. This can be a good reference to future clinical practice.

\section{Declarations}

a. Funding: Not applicable.

b. Conflicts of interest/Competing interests : Not applicable.

c. Availability of data and material: The datasets used or analysed during the current study are available from the corresponding author on reasonable request.

d. Code availability: All models or code generated or used during the study are proprietary or confidential in nature and may only be provided with restrictions

e. Ethics approval: Not applicable.

f. Authors' contributions: WP Xiang and L Che wrote the manuscript with support from XD Cai and WJ Lai. M Zhang and WT Gao conducted the main analysis. T Tian,GJ Chen,Y Yang, YS Huang, MM Zhang, YR Zhang, SM Liu helped data collection and supervision of the project.

g. Consent to participate: Not applicable.

h. Consent for publication : Not applicable.

\section{Reference}

1. Chen, X., Liu, S., Goraya, M. U., Maarouf, M., Huang, S., \& Chen, J. L. (2018). Host Immune Response to Influenza A Virus Infection. Frontiers in immunology, 9, 320. https://doi.org/10.3389/fimmu.2018.00320

2. Kim, H., Webster, R. G., \& Webby, R. J. (2018). Influenza Virus: Dealing with a Drifting and Shifting Pathogen. Viral immunology, 31(2), 174-183. https://doi.org/10.1089/vim.2017.0141

3. Epperson, S., Davis, C. T., Brammer, L., Abd Elal, A. I., Ajayi, N., Barnes, J., Budd, A. P., Burns, E., Daly, P., Dugan, V. G., Fry, A. M., Jang, Y., Johnson, S. J., Kniss, K., Kondor, R., Grohskopf, L. A., Gubareva, L., Merced-Morales, A., Sessions, W., Stevens, J., .. Jernigan, D. (2019). Update: Influenza Activity - United States and Worldwide, May 19-September 28, 2019, and Composition of the 2020 Southern Hemisphere Influenza Vaccine. MMWR. Morbidity and mortality weekly report, 68(40), 880-884. https://doi.org/10.15585/mmwr.mm6840a3

4. WHO. Influenza. https://www.who.int/biologicals/vaccines/influ enza/en/. Accessed 27 May 2019.

5. Park, J. E., \& Ryu, Y. (2018). Transmissibility and severity of influenza virus by subtype. Infection, genetics and evolution : journal of molecular epidemiology and evolutionary genetics in infectious diseases, 65 , 288-292. https://doi.org/10.1016/j.meegid.2018.08.007

1. Martínez, A., Soldevila, N., Romero-Tamarit, A., Torner, N., Godoy, P., Rius, C., Jané, M., Domínguez, À., \& Surveillance of Hospitalized Cases of Severe Influenza in Catalonia Working Group (2019). Risk factors associated with severe outcomes in adult hospitalized patients according to influenza type and subtype. PloS one, 14(1), e0210353. https://doi.org/10.1371/journal.pone.0210353

2. Streng, A., Prifert, C., Weissbrich, B., Sauerbrei, A., Schmidt-Ott, R., \& Liese, J. G. (2018). Subtypespecific Clinical Presentation, Medical Treatment and Family Impact of Influenza in Children 1-5 Years of Age Treated in Outpatient Practices in Germany During Three Postpandemic Years, 2013-2015. The Pediatric infectious disease journal, 37(9), 861-867. https://doi.org/10.1097/INF.0000000000001935

3. Fu, X., Zhou, Y., Wu, J., Liu, X., Ding, C., Huang, C., Zheng, S., Vijaykrishna, D., Chen, Y., Li, L., \& Yang, S. (2019). Clinical characteristics and outcomes during a severe influenza season in China during 2017-2018. BMC infectious diseases, 19(1), 668. https://doi.org/10.1186/s12879-019-4181-2 
4. Beard KR, Brendish NJ, Clark TW. Treatment of influenza with neuraminidase inhibitors. Curr Opin Infect Dis. 2018 Dec;31(6):514-519. doi: 10.1097/QCO.0000000000000496.

5. Mosnier, A., Caini, S., Daviaud, I., Nauleau, E., Bui, T. T., Debost, E., Bedouret, B., Agius, G., van der Werf, S., Lina, B., Cohen, J. M., \& GROG network (2015). Clinical Characteristics Are Similar across Type A and B Influenza Virus Infections. PloS one, 10(9), e0136186. https://doi.org/10.1371/journal.pone.0136186

1. Uyeki, T. M. , Bernstein, H. H. , Bradley, J. S. , Englund, J. A., File, T. M. , \& Fry, A. M. , et al. (2018). Clinical practice guidelines by the infectious diseases society of america: 2018 update on diagnosis, treatment, chemoprophylaxis, and institutional outbreak management of seasonal influenzaa. Clinical Infectious Diseases. 8(6):895-902. https://doi.org/10.1093/cid/ciy866

2. Yap, J., Tan, C. H., Cook, A. R., Loh, J. P., Tambyah, P. A., Tan, B. H., \& Lee, V. J. (2012). Differing clinical characteristics between influenza strains among young healthy adults in the tropics. BMC infectious diseases, 12, 12. https://doi.org/10.1186/1471-2334-12-12

3. Zhu, A., Liu, J., Ye, C., Yu, J., Peng, Z., Feng, L., Wang, L., Qin, Y., Zheng, Y., \& Li, Z. (2020). Characteristics of Seasonal Influenza Virus Activity in a Subtropical City in China, 2013-2019. Vaccines, 8(1), 108. https://doi.org/10.3390/vaccines8010108

4. Torcia, M. G., Nencioni, L., Clemente, A. M., Civitelli, L., Celestino, I., Limongi, D., Fadigati, G., Perissi, E., Cozzolino, F., Garaci, E., \& Palamara, A. T. (2012). Sex differences in the response to viral infections: TLR8 and TLR9 ligand stimulation induce higher IL10 production in males. PloS one, 7(6), e39853. https://doi.org/10.1371/journal.pone.0039853

5. Yang, J. H., Huang, P. Y., Shie, S. S., Yang, S., Tsao, K. C., Wu, T. L., Leu, H. S., \& Huang, C. T. (2015). Predictive Symptoms and Signs of Laboratory-confirmed Influenza: A Prospective Surveillance Study of Two Metropolitan Areas in Taiwan. Medicine, 94(44), e1952. https://doi.org/10.1097/MD.0000000000001952

6. Shah, S. C., Rumoro, D. P., Hallock, M. M., Trenholme, G. M., Gibbs, G. S., Silva, J. C., \& Waddell, M. J. (2015). Clinical predictors for laboratory-confirmed influenza infections: exploring case definitions for influenza-like illness. Infection control and hospital epidemiology, 36(3), 241-248. https://doi.org/10.1017/ice.2014.64

7. Lam, P. P., Coleman, B. L., Green, K., Powis, J., Richardson, D., Katz, K., Borgundvaag, B., SmithGorvie, T., Kwong, J. C., Bondy, S. J., \& McGeer, A. (2016). Predictors of influenza among older adults in the emergency department. BMC infectious diseases, 16(1), 615. https://doi.org/10.1186/s12879016-1966-4

8. Irving, S. A., Patel, D. C., Kieke, B. A., Donahue, J. G., Vandermause, M. F., Shay, D. K., \& Belongia, E. A. (2012). Comparison of clinical features and outcomes of medically attended influenza A and influenza B in a defined population over four seasons: 2004-2005 through 2007-2008. Influenza and other respiratory viruses, 6(1), 37-43. https://doi.org/10.1111/j.1750-2659.2011.00263.x

9. Caini, S., Kroneman, M., Wiegers, T., El Guerche-Séblain, C., \& Paget, J. (2018). Clinical characteristics and severity of influenza infections by virus type, subtype, and lineage: A systematic literature review. Influenza and other respiratory viruses, 12(6), 780-792. https://doi.org/10.1111/irv.12575

10. Rello, J., \& Pop-Vicas, A. (2009). Clinical review: primary influenza viral pneumonia. Critical care (London, England), 13(6), 235. https://doi.org/10.1186/cc8183

11. Lee, C. S., Lee, J. H., \& Kim, C. H. (2011). Time-dependent sensitivity of a rapid antigen test in patients with 2009 H1N1 influenza. Journal of clinical microbiology, 49(4), 1702. https://doi.org/10.1128/JCM.02247-10

12. Chartrand, C., Leeflang, M. M., Minion, J., Brewer, T., \& Pai, M. (2012). Accuracy of rapid influenza diagnostic tests: a meta-analysis. Annals of internal medicine, 156(7), 500-511. https://doi.org/10.7326/0003-4819-156-7-201204030-00403

13. Esposito, S., Cantarutti, L., Molteni, C. G., Daleno, C., Scala, A., Tagliabue, C., Pelucchi, C., Giaquinto, C., \& Principi, N. (2011). Clinical manifestations and socio-economic impact of influenza among healthy children in the community. The Journal of infection, 62(5), 379-387. https://doi.org/10.1016/j.jinf.2011.02.015 
14. Caini, S., Kroneman, M., Wiegers, T., El Guerche-Séblain, C., \& Paget, J. (2018). Clinical characteristics and severity of influenza infections by virus type, subtype, and lineage: A systematic literature review. Influenza and other respiratory viruses, 12(6), 780-792. https://doi.org/10.1111/irv.12575

15. GL Ridgway. (1990). Principles and practice of infectious diseases. Travel Medicine \& Infectious Disease, 8(5), 326-326. https://doi.org/10.1016/j.tmaid.2010.07.004

16. McBean, A. M., \& Hebert, P. L. (2004). New estimates of influenza-related pneumonia and influenza hospitalizations among the elderly. International journal of infectious diseases : IJID : official publication of the International Society for Infectious Diseases, 8(4), 227-235. https://doi.org/10.1016/j.ijid.2004.04.013

17. Thompson, W. W., Shay, D. K., Weintraub, E., Brammer, L., Bridges, C. B., Cox, N. J., \& Fukuda, K. (2004). Influenza-associated hospitalizations in the United States. JAMA, 292(11), 1333-1340. https://doi.org/10.1001/jama.292.11.1333

18. Avni, T., Babich, T., Nir, A., Yahav, D., Shaked, H., Sorek, N., Zvi, H. B., Bishara, J., \& Atamna, A. (2020). Comparison of clinical outcomes of influenza A and B at the 2017-2018 influenza season: a cohort study. European journal of clinical microbiology \& infectious diseases : official publication of the European Society of Clinical Microbiology, 39(6), 1109-1114. https://doi.org/10.1007/s10096-020$03822-\mathrm{x}$

19. Curbelo, J., Rajas, O., Arnalich, B., Galván-Román, J. M., Luquero-Bueno, S., Ortega-Gómez, M., Lancho, A., Roy, E., Sánchez Azofra, A., Mateo Jiménez, G., Gómez, M., Moldenhauer, F., \& Aspa, J. (2019). Neutrophil Count Percentage and Neutrophil-Lymphocyte Ratio as Prognostic Markers in Patients Hospitalized for Community-Acquired Pneumonia. Estudio del porcentaje de neutrófilos y el cociente de neutrófilos-linfocitos como marcadores pronósticos en pacientes hospitalizados por neumonía adquirida en la comunidad. Archivos de bronconeumologia, 55(9), 472-477. https://doi.org/10.1016/j.arbres.2019.02.005

20. Mancinelli, L., Onori, M., Concato, C., Sorge, R., Chiavelli, S., Coltella, L., Raucci, U., Reale, A., Menichella, D., \& Russo, C. (2016). Clinical features of children hospitalized with influenza A and B infections during the 2012-2013 influenza season in Italy. BMC infectious diseases, 16, 6. https://doi.org/10.1186/s12879-015-1333-x 